\title{
MIMICRY OF HYMENOPTERAN ANTENNAE BY SYRPHIDAE*
}

\author{
By G. P. Waldbauer \\ Department of Entomology \\ University of Illinois
}

Many flies of the Family Syrphidae mimic aculeate Hymenoptera. The hymenopterans, particularly vespid wasps, which serve as models for these syrphids have relatively long, many segmented, filiform antennae which are often in motion and are usually a conspicuous feature. Most syrphids, like all of the other cyclorrhaphous Diptera, have three-segmented antennae which are usually short and decidedly inconspicuous as, for example, are those of the non-mimetic Tropidia quadrata (Say) (fig. I). To human eyes the absence of conspicuous antennae decreases the resemblance of mimic to model, and the effect is presumably the same to at least some of the species of predators which are to varying degrees deceived by the mimetic resemblance. I have observed in nature several species of wasp-mimicking syrphids which either have or give the appearance of having long, filiform antennae. In each case the living mimic is remarkably deceptive and only close observation reveals that wasp-like antennae are not actually present.

The antennac of Sphecomyia vittata (Wiedemann) (fig. 2) and Ceriana signifera (Loew) (fig. 3) have been lengthened. The first and second segments of the antennae of $S$. vittata are very long while the third is short and bears an arista. The apparent length of the antennae is further increased by the forward-extending process of the head capsule which bears them. In C. signifera the first and third segments are quite long while the second is of only moderate length. The third segment bears a terminal style rather than an arista, further extending its length. In life both species hold the antennae in positions which suggest the geniculate antennae of vespids.

The antennae of Tenthredomyia abbreviata (Loew) (fig. 4) appear to be long because they are borne by a long, forward-extending process of the head capsule. The antennae themselves have been but slightly lengthened. The first segment is moderately long, but the second and third are short although the third bears a terminal style rather than an arista. As in the preceding two species living specimens of $T$. abbreviata hold the antennae in such a way that they appear

*Manuscript received by the editor January 19, 1970. 


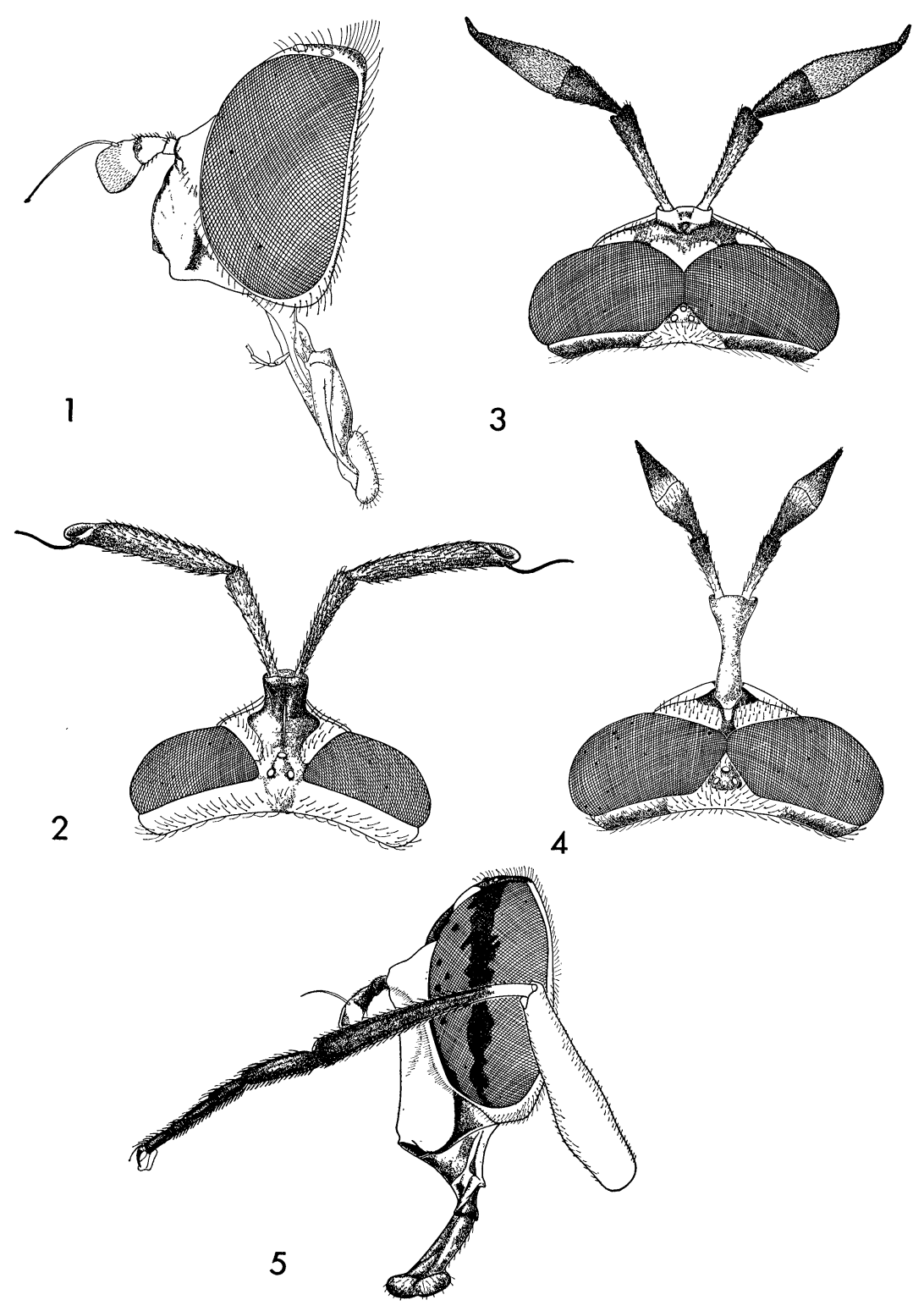


to be geniculate as are the antennae of the models. This orientation is retained even in some dried specimens.

Spilomyia hamifera Loew (fig. 5) has antennae which are short and quite inconspicuous, similar in length and form to the antennae of non-mimetic Syrphidae (fig. I). They are borne by a tubercle which is only slightly produced. In this case the long, dark, filiform antennae of the models are mimicked by the dark front legs which are held up and waved about in front of the head. The effect is very realistic and can easily deceive an inexperienced collector. The tarsi and the distal portion of the tibiae of the front legs are dark. The proximal portion of the front legs as well as the other two pairs of legs are yellow as are those of the models. I have observed this behavior in $S$. hamifera both while they were feeding on flowers or resting on foliage. Occasionally, all six legs are on the substrate, the usual position for most syrphids. I do not know in what position the legs are held in flight.

I have observed a similar use of the front legs in three other vespid-mimicking Spilomyia, S. fusca Loew, S. longicornis Loew and S. quadrifasciata (Say). In each of these species the front tarsi and a part of the front tibiae are dark. The remaining legs are yellow except for dark areas on the femora of $S$. fusca and $S$. quadrifasciata. The legs of $S$. crandalli Curran and $S$. foxleei Vockeroth are similar to those of the last two species mentioned although the meso- and metatarsi of $S$. foxleei are somewhat darkened distally. S. kahli Snow does not have the front legs darkened. I have seen only pinned specimens of the last three species. It may be that $S$. kahli does not use the front legs to mimic antennae, but it seems more likely that models with yellow antennae will be found to occur within its range in the southwestern United States. Curran (195I) stated that all species of Spilomyia rest on the four posterior legs and use the front legs to mimic antennae.

At least some of the North American species of Temnostoma use the front legs in the same manner. In nature $I$ have seen this done by $T$. balyras Walker, $T$. pictulum Williston and $T$. trifasciatum Robertson. In each of these species the front legs are dark while the other two pairs are largely yellow. Although I have not seen them

Figs. 1-5. Dorsal and lateral views of the heads of five species of Syrphidae.

Fig. 1. Tropidia quadrata (Say). Fig. 2. Sphecomyia vittata (Wiedemann). Fig. 3. Ceriana signifera (Loew). Fig. 4. Tenthredomyia abbreviata (Loew). Fig. 5. Spilomyia hamifera Loew. 
in life I have examined dried specimens of $T$. alternans Loew and $T$. vespiforme (L.) and found the legs to be similarly marked.

These observations show that in the Family Syrphidae there are at least four ways of achieving the appearance of aculeate antennae. These four ways represent at least three and perhaps four independent evolutionary innovations. Spilomyia and Sphecomyia certainly present evolutionarily independent solutions to the problem of mimicking hymenopteran antennae. Ceriana and Tenthredomyia represent at least a third line and may have evolved solutions independently of each other. The antennae of both are stylate and otherwise similar. The antennae of Tenthredomyia are borne by a long process, but Ceriana exhibits a similar though very short process. Thus it is possible that these two genera present primitive and advanced versions of the same evolutionary line rather than two separate lines. The question cannot be decided on the basis of the present evidence.

Nicholson ( 1927) noted that among the Syrphidae long antennae are generally associated with those species in which the over-all mimetic resemblance to Hymenoptera is the most highly developed. My observations of living Syrphidae in the eastern United States confirm this view. I have seen very few non-mimetic syrphids which have or appear to have long antennae. In life the species mentioned above are remarkably vespid-like both in general appearance and behavior. However, they are not necessarily precise mimics of a particular species of vespid. I would, nevertheless, consider them to be specialized mimics which exhibit a number of different adaptations which imitate salient features of vespids. For exampie, of the four mimetic species illustrated, all have a more or less distinct dark area along the leading edge of the wing, suggesting the dark band produced by the longitudinal folding of the vespid wing at rest. The four species illustrated also have either a constriction at the base of the abdomen or markings which suggest such a constriction.

It is noteworthy that stylate antennae occur in only three of the 88 genera (Ceriana, Tenthredomyia and Callicera) and I7 of the 939 species of North American Syrphidae listed by Wirth et al. (1965). The genera Ceriana and Tenthredomyia include thirteen species which occur in America north of Mexico. All are wasp mimics. There are four species of Callicera in the same area. The one species which I have seen is not a wasp mimic and is probably not mimetic at all.

In my experience syrphids which mimic bees neither have nor give the appearance of having long antennae. From observations of living 
insects in the field I have found this to be true of Mallota bautius (Walker), M. posticata (Fab.), Eristalis bardus (Say) and E. bastardii Macquart, all of which mimic bumblebees. It is also true of Eristalis tenax (L.) which is frequently cited as a mimic of the honeybee. Another bumblebee mimic, Volucella bombylans (L.), has a rather long and feathery arista which is somewhat conspicuous in the field, but does not suggest to me the antenna of a bumblebee. It would be interesting to know if it is a valid generalization that bee-mimicking syrphids do not appear to have long antennae and, if so, to attempt to discover why this is the case.

Acknowledgment: Thanks are due to Mrs. Alice Prickett who made the drawings.

Curran, C. H.

\section{References Cited}

1951. Synopsis of the North American species of Spilomyia (Syrphidae, Diptera). Amer. Mus. Nat. Hist., Amer. Mus. Novitates 1492: $1-11$.

Nicholson, A. J.

1927. A new theory of mimicry in insects. Austr. Zool. Sydney 5: $10-104+14$ pls.

Wirth,..W. W., Y. S. SEDMAN AND H. V. WeEMs, JR.

1965. Family Syrphidae. p. 557-625. In A. Stone, C. W. Sabrosky, W. W. Wirth, R. H. Foote and J. R. Coulson [ed.], A Catalog of the Diptera of America North of Mexico. U.S.D.A., Agric. Handbook no. 276. 

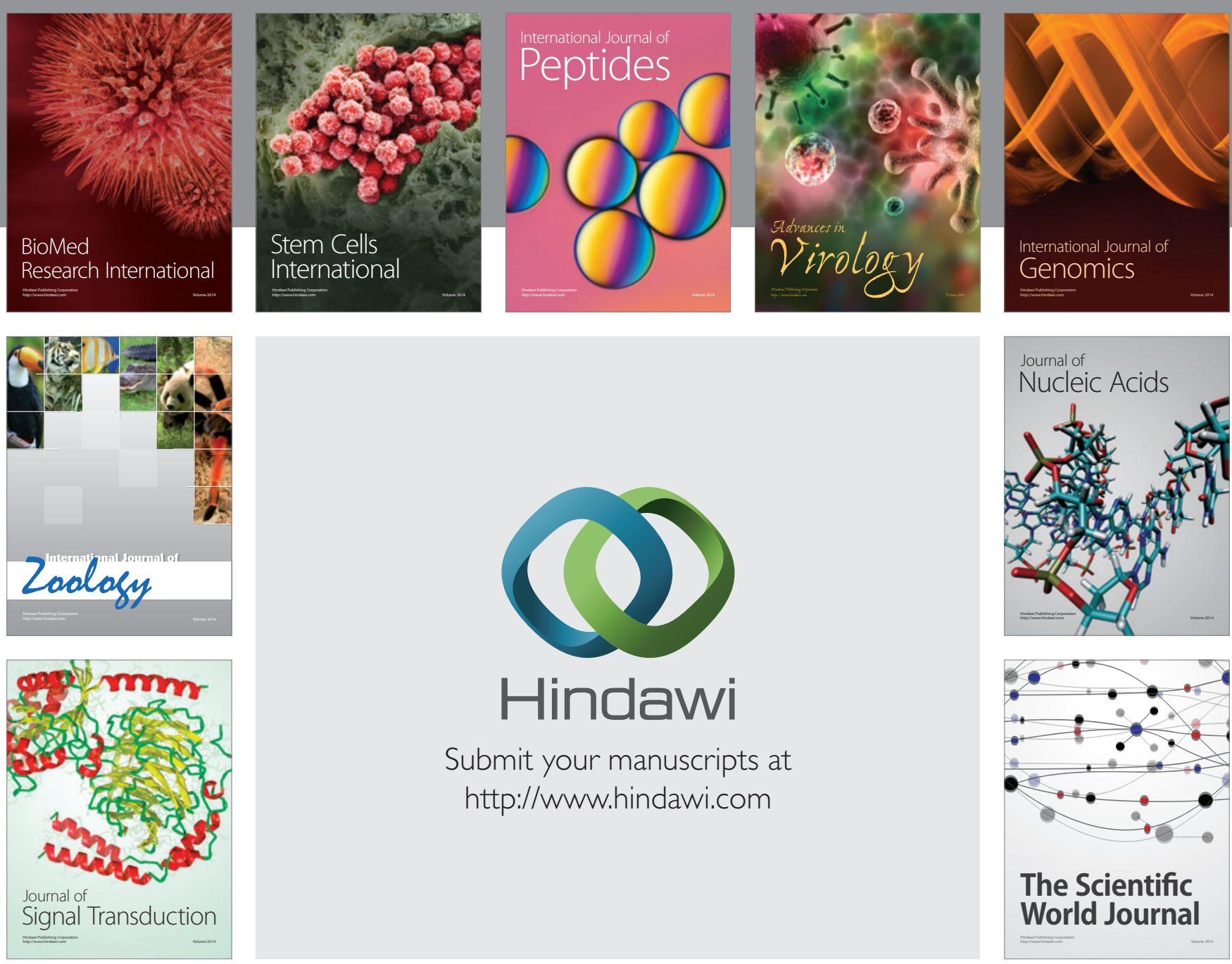

Submit your manuscripts at

http://www.hindawi.com
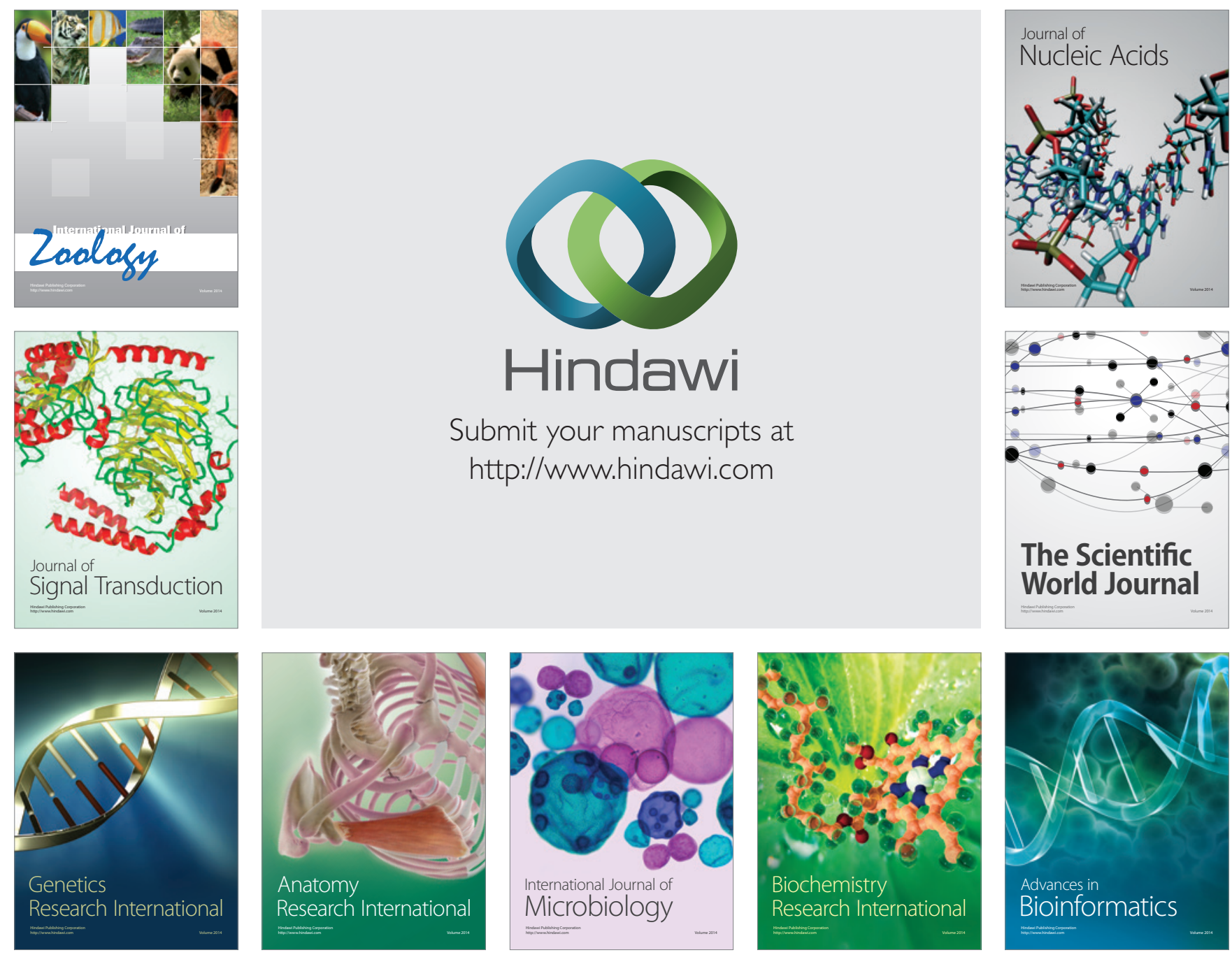

The Scientific World Journal
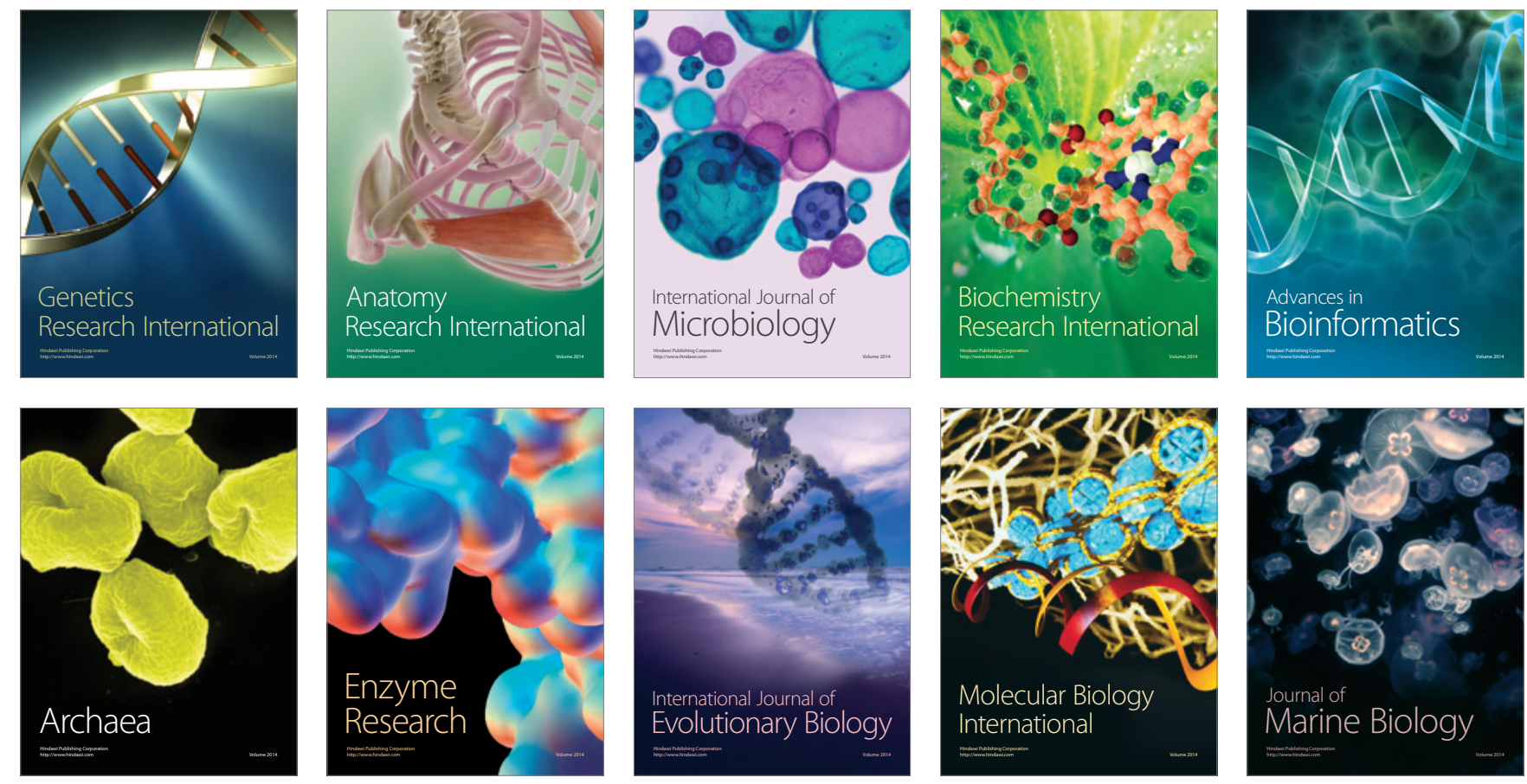